\title{
Desenvolvimento e padronização do Dot-ELISA usando peptídeos recombinantes para o diagnóstico sorológico de Neospora caninum ${ }^{1}$
}

\author{
Rafael D. Blanco ${ }^{2 *}$, Cintia F. Fidelis 2 , Leandro S. Araujo², Adriana M. Henao², Jose A. \\ Cardona $^{2,3}$, Jose D. Guimarães ${ }^{4}$, Marlene I. Vargas $^{5}$ e Joaquin H. Patarroyo ${ }^{6}$
}

\begin{abstract}
Blanco R.D., Fidelis C.F., Araujo L.S., Henao A.M., Cardona J.A., Guimarães J.D., Vargas M.I. \& Patarroyo J.H. 2014. [Development and standardization of Dot-ELISA using recombinant peptides for serological diagnosis of Neospora caninum.] Desenvolvimento e padronização do Dot-ELISA usando peptídeos recombinantes para o diagnóstico sorológico de Neospora caninum. Pesquisa Veterinária Brasileira 34(8):723-727. Laboratório de Biologia e Controle de Hematozoários e Vetores, Universidade Federal de Viçosa, Avenida Ph Rolfs, Campus Universitário, Viçosa, MG 36570-000, Brazil. E-mail: rdblama@gmail.com

Neosporosis is recognized as a major cause of abortion and neonatal loss in cattle worldwide, both for dairy cattle and beef cattle. In recent years this disease has attracted the interest of researchers and studying the epidemiology and effective methods of diagnosis of this disease. The present study aimed to develop and standardize on a Dot-ELISA for the serological diagnosis of Neospora caninum by using recombinant peptide as antigen for the development of a diagnostic kit used on the field. The recombinant antigen (rNcGRA1) was designed based on the method of reverse genetics derived antigenic epitopes of dense granules protein of $N$. caninum and synthesized by GenScript (USA). It was produced by the fermentation in yeasts Pichiapastoris KM71. The serological technique was used for the Dot-ELISA detection of IgG specific for $N$. caninum in which $0.22 \mu \mathrm{m}$ nitrocellulose membranes were sensitized with $1 \mu \mathrm{L}$ of antigen and subsequently the plasmas were diluted in a washing solution and incubated for 1 hour. The results will revealed by the addition of Protein $\mathrm{G}$ labeled with peroxidasse for 30 minutes, followed by the developing solution based on 3,3'-Diaminobenzidine (DAB). Soon after standardization tested 44 bovine plasmas were diagnosed by indirect immunofluorescence assay (IFA), agreeing with the results on a $95.5 \%$ and a sensitivity and specificity of $100 \%$ and $92 \%$ respectively. In regard to the diagnostic kit for the Technology Platform Rapid Flow-Through Miriad ${ }^{\circledR}$, the peptide presented rNcGRA1 visible markings to react with positive plasma, and showed no markings using the negative plasma. This study is the first to use recombinant peptides and prove to be efficient for the serological diagnosis of cattle naturally infected.
\end{abstract}

INDEX TERMS: Neosporosis, Neospora caninum, diagnosis, parasitic diseases, hematozoários, Dot-ELISA, sorology, cattle.

RESUMO.- A neosporose é reconhecida como uma das maiores causas de aborto e perdas neonatais em bovinos de leite e corte em todo o mundo. Nos últimos anos esta

\footnotetext{
${ }^{1}$ Recebido em 21 de janeiro de 2014.

Aceito para publicação em 29 de março de 2014.

${ }^{2}$ Pós-Graduação em Medicina Veterinária, Laboratório de Biologia e Controle de Hematozoários e Vetores (Bioagro), Universidade Federal de Viçosa (UFV), Avenida Peter Henry Rolfs s/n, Campus Universitário, Viçosa, MG 36570-000, Brasil. *Autor para correspondência: rdblama@ gmail.com
}

doença tem atraído o interesse de pesquisadores com foco na epidemiologia e métodos eficazes de diagnóstico desta doença. No presente estudo objetivou-se desenvolver e pa-

\footnotetext{
${ }^{3}$ Docente de Clínica de Grandes Animais, Facultad de Medicina Veterinaria y Zootecnia, Universidad de Córdoba, AA 354 Montería, Colômbia.

${ }^{4}$ Docente de Reprodução Animal, Depto Medicina Veterinária, UFV, Viçosa, MG.

${ }^{5}$ Docente de Patologia Veterinária, Departamento de Medicina Veterinária, UFV, Viçosa, MG.

${ }^{6}$ Docente de Doenças Parasitárias, Departamento de Medicina Veterinária, UFV, Viçosa, MG.
} 
dronizar um teste Dot-ELISA para o diagnóstico sorológico de Neospora caninum com um peptídeo recombinate como antígeno, visando o desenvolvimento de um kit para diagnóstico a campo. 0 peptídeo recombinante (rNcGRA1) foi desenhado com base na metodologia de genética reversa de epítopos antigênicos originados de uma proteína de grânulos densos de N. caninum, e sintetizado pela GenScript (USA). Produzido mediante o processo fermentativo em leveduras Pichia pastoris KM71. Para a padronização do Dot-ELISA, membranas de nitrocelulose de $0.22 \mu \mathrm{m}$ foram sensibilizadas com $1 \mu \mathrm{L}$ do antígeno e posteriormente os soros foram diluídos em solução de lavagem e incubados durante 1 hora. A revelação foi feita mediante a adição de Proteína $\mathrm{G}$ marcada com peroxidase por 30 minutos, seguido da solução reveladora a base de 3,3'-Diaminobenzidine (DAB). Logo após a padronização foram testados 44 soros bovinos diagnosticados por imunofluorescência indireta (RIFI), obtendo-se uma concordância nos resultados do teste de $95,5 \%$ e uma sensibilidade e especificidade de $100 \%$ e 92\% respectivamente. Quanto ao Kit para diagnóstico a campo na Plataforma Tecnológica RapidFlow-Through Mi$\operatorname{riad}{ }^{\circledR}$, o peptídeo $r$ NcGRA1 apresentou marcações visíveis ao reagir com os soros positivos, e não apresentou marcações usando os soros negativos. Este estudo é o primeiro a utilizar peptídeos recombinantes e mostrar-se eficiente para o diagnóstico sorológico de bovinos naturalmente infetados por N. caninum.

TERMOS DE INDEXAÇÃO: Neosporose, Neospora caninum, diagnóstico, doenças parasitarias, hematozoários, Dot-ELISA, sorologia, bovinos.

\section{INTRODUÇÃO}

Neospora caninum é um parasito intracelular obrigatório, formador de cistos, capaz de infectar uma série de hospedeiros de interesse produtivo, principalmente ruminantes (Yao et al. 2009). Os cães e coiotes são os hospedeiros definitivos do coccídeo, eliminando oocistos em suas fezes (Gondim et al. 2004).

A transmissão vertical em bovinos é considerada a principal via de transmissão do parasito (Trees \& Willians, 2005), assumindo papel primordial na manutenção da doença, pelo fato da maioria das infecções congênitas resultar em animais clinicamente normais, mas persistentemente infectados(Yildiz et al. 2009). A doença é caracterizada por abortos, sendo o único sinal aparente da doença (Dubey \& Schares, 2011), podendo ocorrer entre o quinto e o sexto mês de gestação, embora possam se apresentar a partir do terceiro mês até o término da gestação (Dubey, 1999).

A primeira evidência sorológica de infecção por Neospora caninum em bovinos no Brasil foi feita no ano 1996, no estado de São Paulo em bovinos de corte e leite com histórico de aborto (Brautigan et al. 1996). A partir do primeiro isolamento de $N$. caninum, testes sorológicos como a reação de imunofluorescência indireta (RIFI), teste de aglutinação de Neospora (TAN) e teste imunoenzimático (ELISA) foram desenvolvidos para o diagnóstico em cães, bovinos e outros animais hospedeiros potenciais (Atkinson et al. 2000).

As técnicas de imunodiagnóstico avaliam o contato do hospedeiro com o agente por meio da detecção de IgG, sen- do as mais comuns a RIFI e o teste ELISA. A primeira é uma técnica que pode ser considerada de leitura subjetiva, além de necessitar de equipamentos de alto custo. A desvantagem do teste de ELISA é que os antígenos ainda não são produzidos no Brasil, limitando a execução do teste por causa do alto custo de importação.

O Dot-ELISA é uma técnica usada com menor frequência para o diagnóstico da neosporose. É uma técnica baseada na sensibilização de membranas de nitrocelulose com antígeno, e posterior adição de um anticorpo marcado com peroxidase, para ocorrência de reação e revelação com formação de cor. 0 principio é semelhante ao ELISA; no entanto, não requer aparelhagem sofisticada (Pinheiro 2001. Pinheiro et al. 2006). Alem disso é um teste objetivo onde a reação com formação de cor indica a soropositividade e a ausência de cor indica a soronegatividade, não tendo outras formas de leitura que façam deste um teste subjetivo. Pode ser usado como método quantitativo, quando se deseja verificar a concentração do antígeno, ou, ainda qualitativo, separando amostras em positivas ou negativas (Pinheiro 2001).

Por ser uma técnica de imunodiagnóstico de fácil execução e eficaz, o presente estudo objetivou desenvolver e padronizar um Dot-ELISA para o diagnóstico sorológico de Neospora caninum a partir do uso de peptídeo recombinante como antígeno, visando o desenvolvimento de kit para diagnóstico a campo.

\section{MATERIAIS E MÉTODOS}

\section{Produção do antígeno}

Um gene sintético, contendo os principais epítopos antigênicos da proteína de grânulos densos do parasito, NcGRA1 (GenBank: AF199030.1), foi desenhado através da metodologia de genética reversa de epítopos antigênicos determinados por ferramentas de bioinformática. Seus códons foram otimizados para a expressão em Pichia pastoris KM71, que foi transformada como plasmídio linearizado, gerando transformantes estáveis via recombinação homóloga entre o DNA transformante e regiões de homologia dentro do genoma da levedura. Posteriormente a confirmação da recombinação gênica na P. pastoris KM71 e sua transformação foram realizadas através da técnica de reação em cadeia da polimerase (PCR) do material genético extraído das colônias selecionadas seguindo recomendações do manual do Sistema de expressão em Pichia pastoris (Invitrogen ${ }^{\circledR}$ ).

A produção dos antígenos recombinantes, em escala laboratorial, foi realizada por processos fermentativos em frascos "spinner" (fermentadores de bancada) de $500 \mathrm{ml}$, com injeção contínua de oxigênio, rotação de $250 \mathrm{rpm}$ e temperatura de $30^{\circ} \mathrm{C}$. Para isso uma simples colônia foi inoculada em $50 \mathrm{~mL}$ de meio $\mathrm{B}(13 \mathrm{~g}$

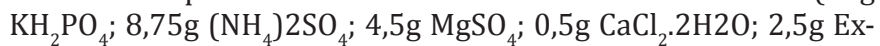
trato de levedura e $40 \mathrm{~mL}$ de glicerol) em erlenmayer de $250 \mathrm{~mL}$ e crescida por cerca de 18 horas à temperatura de $30^{\circ} \mathrm{C}$ e sob agitação orbital constante de $250 \mathrm{rpm}$. Essa cultura foi posteriormente inoculada em $500 \mathrm{~mL}$ do mesmo meio e transferidos para frasco "spinner" devidamente esterilizado. Foi mantida sob essas condições por 2 dias, quando foi alimentada com $40 \mathrm{~mL}$ de solução de glicerol $50 \%$ autoclavada. Posteriormente a batelada foi induzida com $1 \%$ do volume de meio, de metanol diariamente, durante um período de 96 horas. $0 \mathrm{pH}$ foi mantido em 5-5,5 corrigido com hidróxido de amônia 50\% diluído em água Milli-Q autoclavada. Após indução, a cultura foi centrifugada a 3000xg por 15 minutos 
e o sobrenadante submetido a ultra-filtração em membrana de 30 $\mathrm{kDa}$ e $1 \mathrm{kDa}$.

\section{Padronização do Dot-ELISA}

Para padronização da técnica, foram utilizados soros bovinos confirmados por RIFI como negativo e positivo. Após conhecer a concentração do peptídeo recombinante, realizou-se a titulação do antígeno como forma de verificar a menor concentração capaz de promover a reação. Membranas de nitrocelulose de $0,22 \mu \mathrm{m}$ foram sensibilizadas com antígeno diluído em PBS (4,25g NaCl; 0,64g $\mathrm{Na}_{2} \mathrm{HPO}_{4} ; 0,068 \mathrm{NaH}_{2} \mathrm{PO}_{4} \cdot \mathrm{H}_{2} \mathrm{O} ; \mathrm{H}_{2} \mathrm{O}$ deionizada q.s.p. $500 \mathrm{~mL} ; \mathrm{pH}$ $7,6)$ nas concentrações de 0,$5 ; 1,0 ; 1,5$ e $2 \mu \mathrm{g}$ /poço e secas durante duas horas em refrigeração a $4^{\circ} \mathrm{C}$. Cada concentração foi feita em quadruplicata com duas réplicas para cada concentração.

Após sensibilização, foram submetidas a bloqueio com PBST+Caseína 0,3\% (PBS; Tween20; Caseína), por 30 minutos. Logo depois, as membranas foram submetidas a diluições distintas (1:50, 1:100, 1:200 e 1:400) do soro positivo e soro negativo durante uma hora. Posteriormente, as membranas foram lavadas três vezes por cinco minutos sob agitação lenta com PBST a 0,5\% e incubadas com Proteína G marcada com peroxidase em uma diluição de 1:5000, durante 30 minutos. Posteriormente, as membranas foram novamente lavadas duas vezes com PBST a $0,5 \%$ e mais uma vez com PBS. A revelação foi feita mediante a adição de uma solução reveladora a base de 3,3'-Diaminobenzidine (DAB), Tris $50 \mathrm{mM}$, cloreto de níquel ao $0,3 \%$ e água oxigenada $\left(\mathrm{H}_{2} \mathrm{O}_{2}\right)$. A reação ocorreu em 30 segundos e foi parada fazendo duas lavagens com $200 \mu \mathrm{L}$ de água destilada. Todas as etapas foram realizadas em temperatura ambiente sob agitação constante.

Considerou-se como melhor resultado para efeito da padronização, a diluição do antígeno que apresentou melhor definição visual de cor entre o soro positivo e negativo.

\section{Amostras}

Foram utilizadas 44 amostras de sangue de bovinos de diferentes idades provenientes da Unidade de Ensino, Pesquisa e Extensão em Gado de Leite do Departamento de Zootecnia, da Universidade Federal de Viçosa - MG, todas com diagnóstico sorológico de infecção por Neospora caninum por meio de RIFI realizado no laboratório TECSA (Belo Horizonte, MG). Com base no diagnóstico sorológico, os animais foram distribuídos em dois grupos, sendo 22 soropositivos e 22 soronegativos.

As amostras sanguíneas foram encaminhadas ao Laboratório de Biologia e Controle de Hematozoários e Vetores - LBCHV, no Instituto de Biotecnologia Aplicada à Agropecuária - BIOAGRO, onde foram centrifugados a $1500 x g$ por 5 minutos. Os soros foram identificados e armazenados em criotubos e conservados em freezer a $-20^{\circ} \mathrm{C}$, até a realização das análises.

\section{Cálculo de sensibilidade e especificidade}

Para efeito de cálculo da sensibilidade e especificidade do Dot-ELISA, utilizaram-se as fórmulas propostas por Guimarães MCS (1985):

$$
\begin{aligned}
& \text { Sensibilidade }=\frac{\text { Verdadeiros Positivos }}{(\text { Verdadeiros Positivos }+ \text { Falsos Negativos })} \times 100 \\
& \text { Especificidade }=\frac{\text { Verdadeiros Negativos }}{(\text { Verdadeiros Negativos + Falsos Positivos) }} \times 100
\end{aligned}
$$

\section{Desenho do kit para campo}

Para o desenho do kit diagnóstico de Neospora caninum a campo, foi utilizada a Plataforma Tecnológica RapidFlow-Through Miriad $^{\circledR}$ seguindo as indicações do fabricante (MedMira).

\section{RESULTADOS E DISCUSSÃO}

O peptídeo rNcGRA1 se origina de uma proteína dos grânulos denso liberada durante a fase de conversão do estado de taquizoítos a bradizoítos de Neospora caninum. As análises do peptídeo utilizado neste estudo revelaram que o mesmo é composto por 78 aminoácidos, possui peso molecular de $8,08 \mathrm{KDa}$, e ponto isoelétrico de 4,3. Os peptídeos recombinantes apresentam elevada sensibilidade e especificidade para o diagnóstico, sobretudo ausência de reação cruzada. 0 peptídeo rNcGRA1, comparado com 23 milhões de sequências, apresentou 48\% de similaridade com a proteína íntegra GRA1 e 50\% de similaridade com Neospora caninum, cepa Liverpool, sendo um peptídeo recombinante com capacidade de ser reconhecido pelos anticorpos de bovinos e ovinos (Patarroyo et al. 2013) infectados naturalmente.

A quantificação proteica revelou concentração de $4 \mu \mathrm{g} /$ $\mu \mathrm{L}$. No presente estudo, as diferentes concentrações empregadas reagiram aos testes, sendo a concentração ideal considerada para efeito de padronização de $0,5 \mu \mathrm{g} /$ poço, sugerindo que o peptídeo recombinante apresenta uma conformação com características semelhantes às proteínas nativas de $N$. caninum, tendo a capacidade de ser utilizado para o desenvolvimento de métodos de imunodiagnóstico.

Antígenos gerados a partir de domínios de superfície de $N$. caninum já têm sido utilizados, demonstrando resultados satisfatórios com soro bovino e potencial para o desenvolvimento de testes sorológicos específicos para neosporose (Pinheiro et al. 2013). Além disso, o uso de antígenos produzidos em sistema de expressão em levedura tem demonstrado ser geneticamente estável, pois uma vez transformadas, são capazes de crescimento em meios de cultura relativamente simples e de produção em escala industrial (Cereghino et al. 2002). Recentemente, as pesquisas com antígenos recombinantes para o diagnóstico sorológico de $N$. caninum têm sido desenvolvidas usando proteínas de superfície íntegras, sendo este estudo o primeiro a utilizar peptídeos recombinantes contendo fragmentos da proteína íntegra do complexo apical e mostrar eficiência para o diagnóstico da neosporose.

No que se refere à padronização da técnica de imunodiagnóstico, o bloqueio demonstrou ótimo desempenho, e o valor de diluição ótimo dos soros empregados na realização dos testes foi de 1:200. Além disso, a diluição do conjugado a1:5000 forneceu distinção visual entre os soros controles positivo e negativo.

Após a padronização da técnica, com os 44 soros testados no presente estudo, 95,5\% coincidiram com o diagnóstico feito por RIFI (Fig.1), sendo maior que a concordância verificada por Sartor et al.(2003) ao comparar as técnicas de ELISA e RIFI usando uma diluição 1:200, constatando que a ocorrência de anticorpos anti-N. caninum foi $85 \%$ superior na primeira técnica.

O imunodiagnóstico por Dot-ELISA tem sido avaliado e mostrou-se eficiente, tendo concordância entre resultados obtidos pelo teste ELISA comercial e o Dot-ELISA em soros de bovinos (Ahmad et al. 2011). No presente estudo, de acordo com os soros avaliados, verificou-se uma sensibilidade e especificidade de $100 \%$ e $92 \%$ respectivamente, índices que superam os valores relatados por Ahmad et al. 


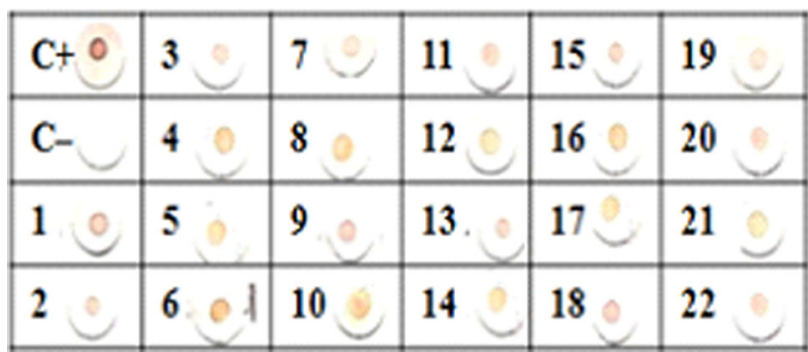

\begin{tabular}{|l|l|l|l|l|l|}
\hline $\mathrm{C}+$ & 25 & 29 & 33 & 37 & 41 \\
\hline $\mathrm{C}-$ & 26 & 30 & 34 & 38 & 42 \\
\hline 23 & 27 & 31 & 35 & 39 & 43 \\
\hline 24 & 28 & $32 \smile$ & 36 & 40 & 44 \\
\hline
\end{tabular}

Fig.1. Dot-ELISA utilizando antígeno rNcGRA1 com bovinos soropositivos (à esquerda) e soronegativos (à direita) para Neospora caninum.

(2011), onde reportaram uma sensibilidade de $95 \%$ e especificidade de $88 \%$, utilizando como antígeno taquizoítos de N. canimum.

0 teste padronizado tem a capacidade de reconhecer a presença de IgG específicas para $N$. caninum, sendo um teste capaz de diagnosticar animais clinicamente sadios mas persistentemente infectados. Em bezerros ou bovinos adultos, anticorpos específicos IgG aparecem no sangue poucos dias após a infecção primária e aumentam durante a primeira semana até três a seis meses após a infecção experimental primária (Williams et al. 2000). Permitindo diagnosticar animais em qualquer fase da doença e inclusive com o parasito em período de latência.

Quanto ao teste na Plataforma Tecnológica RapidFlowThroughMiriad @, o peptídeo rNcGRA1 apresentou marcações visíveis ao reagir com os soros positivos, e não apresentou marcações usando os soros negativos. Para uma melhor visualização da marcação, a concentração do antígeno usada foi $1,5 \mu \mathrm{g} / \mu \mathrm{L}$ (Fig.2).

No kit, a proteína G do conjugado se liga aos anticorpos anti-N.caninum do complexo e a concentração do ouro coloidal permitirá a visualização de um ponto colorido (vermelho).0 kit desenhado para o diagnóstico em campo trata de um teste inovador, de fácil leitura, o qual usa proteína G conjugada com ouro coloidal, permitindo uma ligação com o anticorpo específico em segundos, e a totalidade do teste pode ser completada em aproximadamente $12 \mathrm{mi}-$ nutos. Pela praticidade para sua execução, o kit pode ser usado para levantamentos serológicos usando uma gota de sangue ou de soro por tratar-se de um método preciso,
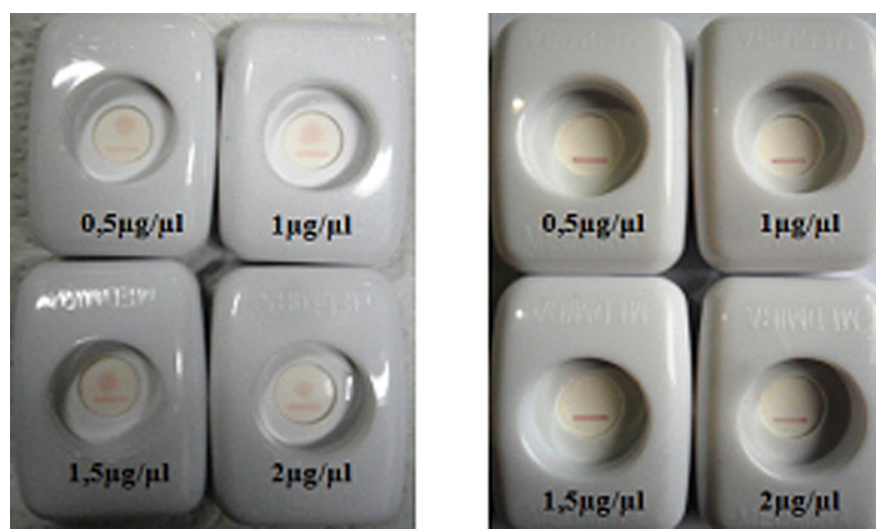

Fig.2. Reação na Plataforma Tecnológica RapidFlow-ThroughMi$\operatorname{riad} 囚$ usando diferentes concentrações do antígeno rNcGRA1 e bovino soropositivo (à esquerda) e soronegativo (à direita) para Neospora caninum. sensível, rápido e facilidade na leitura qualitativa dos dos resultados, onde a formação de um ponto de cor sobre a nitrocelulose é considerado como positivo sem importar a intensidades da marcação.

\section{CONCLUSÕES}

0 uso deste peptídeo recombinante gerado a partir de fragmentos da proteína dos grânulos densos de Neospora caninum (rNcGRA1) mostrou-se eficiente para o diagnóstico sorológico de bovinos naturalmente infetados.

Propõe-se a técnica Dot-ELISA como uma ferramenta de diagnóstico para neosporose com alta sensibilidade e especificidade, além de ser um método rápido e preciso.

O kit para uso a campo é um teste qualitativo, baseado na tecnologia da Plataforma Tecnológica RapidFlowThroughMiriad $^{\circledR}$ com a utilização do peptídeo recombinante capaz de reagir com soros de animais naturalmente infetados, convertendo-se em uma alternativa para veterinários e produtores ao momento de selecionar animais livres da doença.

\section{REFERÊNCIAS}

Ahmad N., Jozani J. \& Neda Z. 2011. Adaptation of Dot-Elisa for serodiagnosis of Neospora caninum infestation in aborted cows. Global Vet. $7(2): 149-152$.

Atkinson R., Harper P.A.W., Reichel M.P. \& Ellis J.T. 2000. Progress in the serodiagnosis of Neospora caninum infections of cattle. Parasitol. Today 16(1):110-114.

Brautigam F.E., Hietala S.K. \& Glass R. 1996. Resultados de levantamento sorológico para a espécie Neospora caninum em bovinos de corte e leite. Anais XV Congresso Panamericano de Ciências Veterinárias, Campo Grande, MS, p.284. (Resumo)

Cereghino G.P.L., Cereghino J.L., Ilgen C. \& Cregg J.M. 2002. Production of recombinant proteins in fermenter cultures of the yeast Pichia pastoris. Curr. Opin. Biotechnol. 13(4):329-332.

Dubey J.P. \& Schares G. 2011. Neosporosis in animals: the last five years. Vet. Parasitol. 180:90-108.

Dubey J.P. 1999. Recent advances in Neospora and neosporosis. Vet. Parasitol. 8(4):349-367.

Gondim L.F.P., McAllister M.M., Pitt W.C. \& Zemlicka D.E. 2004. Coyotes (Canislatrans) are definitive hosts of Neospora caninum. Int. J. Parasitol. 34:159-161.

Guimarães M.C.S. 1985. Exames de laboratorio: sensibilidade, especificidade, valor preditivopositivo. Revta Soc. Bras. Med. Trop. 18:117-120.

Patarroyo J.H., Vargas M.I., Cardona J.A., Blanco R.D. \& Gomez V.E. 2013. Frecuencia serológica de infección por Neospora caninum en ovinos en el departamento de Córdoba, Colombia. MVZ Córdoba 18(3):38863890.

Pinheiro A.F., Borsuk S., Berne M.E., Pinto L.S., Andreotti R., Roos T., Rollof B.C. \& Leite F.P. 2013. Expression of Neospora caninum NcSRS2 surface 
protein in Pichia pastoris and its application for serodiagnosis of Neospora infection. Pathog. Glob. Health 107(3):116-121.

Pinheiro R.R. 2001. Virus da artrite encefalite caprina: desenvolvimento e padronização de ensaios imunoenzimaticos (ELISA e Dot-Blot) e estudo epidemiologico no Estado do Ceará. Dissertação de Doutorado, Escola de Veterinária, Universidade Federal de Minas Gerais, Belo Horizonte, MG.

Pinheiro R.R., Chaves C.D.O., Guimarães A.M.G., Costa S.A. \& Andrioli A. 2006. Desenvolvimento de dot-blot para detecção de anticorpos para o vírus da Artrite Encefalite Caprina em caprinos. Revta Port. Ciênc. Vet. 101:51-56.

Sartor I.F., Hasegawa M.Y., Canavessi A.M.O. \& Pinckney R.D. 2003. Ocorrência de anticorpos de Neospora caninum em vacas leiteiras avaliados pelos métodos de ELISA e RIFI no município de Avaré, SP. Semina, Ciênc. Agrarias 24:3-10

Trees A.J. \& Williams D.J. 2005. Endogenous and exogenous transplacental infection in Neospora caninum and Toxoplasma gondii. Trends Parasitol. 21:558-561.

Williams D.J., Guy C.S., McGarry J.W., Guy F., Tasker L., Smith R.F., MacEachern K., Cripps P.J., Kelly D.F. \& Trees A.J. 2000. Neospora caninum-associated abortion in cattle: the time of experimentally-induced parasitaemia during gestation determines foetal survival. Parasitology 121:347-358.

Yao L., Yang N., Liu Q., Wang M., Zhang W., Qian W.F., Hu Y.F. \& Ding J. 2009. Detection of Neospora caninum in aborted bovine fetuses and dam blood samples by nested PCR and ELISA and seroprevalence in Beijing and Tianjin. Parasitology 136(11):1251-1256.

Yildiz K., Kul O., Babur C., Kilic S., Gazyagci A.N., Celebi B. \& Gurcan I.S. 2009. Seroprevalence of Neospora caninum in dairy cattle ranches with high abortion rate: special emphasis to serologic co-existence with Toxoplasma gondii, Brucella abortus and Listeria monocytogenes. Vet. Parasitol. 164(2):306-310. 